\title{
Comparative effects of Facebook and conventional media on body image dissatisfaction
}

\author{
Rachel Cohen ${ }^{*}$ and Alex Blaszczynski
}

\begin{abstract}
Background: Appearance comparison has consistently been shown to engender body image dissatisfaction. To date, most studies have demonstrated this relationship between appearance comparison and body image dissatisfaction in the context of conventional media images depicting the thin-ideal. Social comparison theory posits that people are more likely to compare themselves to similar others. Since social media forums such as Facebook involve one's peers, the current study aimed to determine whether the relationship between appearance comparison and body image dissatisfaction would be stronger for those exposed to social media images, compared to conventional media images.

Methods: A sample of 193 female first year university students were randomly allocated to view a series of either Facebook or conventional media thin-ideal images. Participants completed questionnaires assessing pre- and post- image exposure measures of thin-ideal internalisation, appearance comparison, self-esteem, Facebook use and eating disorder risk.

Results: Type of exposure was not found to moderate the relationship between appearance comparison and changes in body image dissatisfaction. When analysed according to exposure type, appearance comparison only significantly predicted body image dissatisfaction change for those exposed to Facebook, but not conventional media. Facebook use was found to predict higher baseline body image dissatisfaction and was associated with higher eating disorder risk.

Conclusions: The findings suggest the importance of extending the body image dissatisfaction literature by taking into account emerging social media formats. It is recommended that interventions for body image dissatisfaction and eating disorders consider appearance comparison processes elicited by thin-ideal content on social media forums, such as Facebook, in addition to conventional media.
\end{abstract}

Keywords: Body image dissatisfaction, Social media, Appearance comparison

\section{Background}

Body image dissatisfaction (BID), that is, the negative evaluations of one's physical body, shape and weight [1], has consistently been implicated in the aetiology and maintenance of eating disorders (EDs) [2-4]. High rates of BID are prevalent among young Australian women indicating a need to identify the processes contributing to, and perpetuating, BID [5, 6]. BID is postulated to result from the discrepancy between societal and personal standards of appearance [7]. Accordingly, the mechanism of appearance comparison (AC), involving a direct comparison between such societal and personal standards of appearance,

\footnotetext{
* Correspondence: rach_levy@hotmail.com

School of Psychology, Faculty of Science, The University of Sydney, Camperdown NSW 2006, Australia
}

has been implicated in the development of BID [8]. This relationship between AC and BID has typically and consistently been demonstrated in the context of conventional media images $[9,10]$, whereby women exposed to magazine or television images of 'thin-ideal' models and celebrities engage in appearance-related comparisons and experience greater BID [6, 11-18].

Recent research suggests that social networking sites (SNSs: Facebook and Instagram) are increasingly used by college-aged females as the preferred social resource over conventional media forms, for example magazines and television [19]. Moreover, a growing literature suggests that SNSs have addictive properties [20]. Social comparison theory postulates that individuals are more 
likely to engage in comparisons with similar (peer groups) rather than dissimilar (others) personal attributes [21]. Accordingly, the relationship between AC and BID should be enhanced in SNSs where portrayed females are perceived as real, age- and status-related, and thus more personally identified with in contrast to professional models in conventional media [22].

Studies of self-presentation within SNSs have consistently found that users strategically manipulate their profiles in accordance with societal ideals of attractiveness [23-25]. Women viewing images of professional models represented in conventional forms of media remain aware that these have been digitally enhanced [26] thereby reducing the likelihood of self- comparison and propensity for BID [27]. In contrast, SNS images of 'real' women are assumed to be digitally unaltered and, hence accepted as more accurate and personally relevant [28].

Facebook is a popular SNS [29], with more than a billion active users [30]. Fifty eight percent of users are women [31] with users spending around an average of $16 \mathrm{~h}$ accessing Facebook per month [30]. In Australia there are currently 11,489,580 Facebook users, with the largest age group being 25-34 year-olds, followed by 18-24 year-olds [31].

Social media, unlike conventional media, also provides a virtual forum for fat talk, conversational threads about one's own and other's eating and exercise habits, weight concerns and ideal body shapes [32], thus serving to intensify the influence of AC on BID [33]. Typical Facebook profiles contain strategically selected thin photos of peers coupled with complimentary comments on appearance; for example "you look so skinny and beautiful" [24]. One study [34] found that $70.2 \%$ of profiles of American undergraduate students referenced exercise and $12.3 \%$, eating habits with comments like "just did my morning work-out, feeling great!". Of 600 Facebook users aged 16 to 40, 50 \% reported that Facebook content made them more body-conscious; $31 \%$ feeling "sad" as a result of comparing photos of themselves to those of Facebook friends, and $44 \%$ reported desiring the same body or weight as Facebook friends [35].

Similarly, another study presented participants with a mock Facebook profile-picture and status that expressed a desire to lose weight, followed by their friend's replies either encouraging or discouraging this weight-loss [36]. Participants reported greater BID and lower psychological well-being after reading peer-posted thin-promoting compared to thin- discouraging messages [36].

Time spent on Facebook appears to be associated with BID and ED pathology [37], with the relationship between Facebook and EDs stronger compared to viewing 'Barbie' type models on television and magazines [37]. In addition, adolescent Facebook users also score significantly higher on all body image concern measures than non users [38]. Although the correlational nature of these studies precludes causal inferences, these findings provide strong evidence implicating Facebook use as an emerging risk factor for BID.

It has been shown that conventional media images of the thin-ideal leads to BID via AC. Given the current increasing popularity of social media in comparison to conventional media, it is important to investigate these formats. Of interest is whether this relationship between $\mathrm{AC}$ and BID is stronger for those exposed to social media compared to conventional media. It was hypothesised that, the relationship between appearance comparison and changes in body image dissatisfaction from pre to post-exposure will be stronger for those exposed to Facebook compared to conventional media. Additionally, it was hypothesised that higher Facebook use will predict higher baseline body image dissatisfaction.

\section{Methods}

\section{Participants}

Two hundred and twenty-nine first year university female psychology undergraduate students were recruited through an online advertisement. Of this sample, 22 participants were excluded from analysis because they failed the manipulation check (see below) and 14 participants because they did not complete the full set of questionnaires. This resulted in a final sample size of 193 participants (response rate $=84.1 \%$ ).

An a priori power analysis for a multiple linear regression, assuming a maximum of 6 predictors in the model with a medium effect size $(f 2=.15)$ [39], indicated a total sample of $N=146$ is sufficient to detect a significant difference at $p=0.05$ (actual power $=.952$ ) [40]. Thus the resulting sample of 193 participants was sufficient.

Participants received course credit for participating in the study. Ages ranged from 17 to 46 years $(M=19.32$, $S D=3.47)$. Of the sample, $n=90(47.4 \%)$ participants were Caucasian, $n=68$ (35.8 \%) Asian, $n=7$ (3.7 \%) Middle Eastern, $n=1(0.5 \%)$ Aboriginal/Torres Strait Islander, and $n=1(0.5 \%)$ African and $n=23(12.1 \%)$ other. One hundred and eighty-five (95\%) participants reported having a Facebook account, 6 (3\%) did not have one, and 3 (1.5 \%) failed to indicate. Participants spent an average 15.78 h $(S D=12.62$, Range $=0-59.5)$ accessing Facebook each week. Participants were randomly allocated to either the Facebook $(n=102)$ or conventional media $(n=91)$ stimuli condition using the Qualtrics software program's randomization function.

\section{Design}

The study used a $2 \times(2)$ mixed design. The between-group factor was type of exposure, and within-group factor, pre- to post-exposure. The dependent variables were appearance comparison (AC) and body image dissatisfaction change (BID-change) calculated by subtracting 
pre-exposure from post-exposure BID. Covariates were baseline thin-ideal internalisation, self-esteem and BMI.

\section{Materials}

\section{Experimental stimuli}

Facebook stimuli

Facebook stimuli consisted of ten slides depicting five mock profile-pages. The profiles were designed to reflect the realistic experience of viewing actual Facebook profiles. There were two slides per profile: thin-ideal profile-pictures (depicting thin females, comparable to those in the conventional media images), status', peer comments, 'tagged' pictures and adverts in the side-bar, and; a 'zoomed-in' profile or tagged picture inclusive of friends' comments as displayed when clicking on the picture. The presentation of Facebook stimuli in this way was intended to simulate a more realistic experience of Facebook, and to reflect the interactive nature of SNSs compared to conventional media images.

Stimuli were selected based on the ratings of a convenience sample of ten independent female university students. In order to ensure that the images were reflective of both attractive and thin images, raters viewed a series of 20 Facebook images and indicated the extent to which these were attractive and reflecting a thin-ideal using a 5-point Likert scale ranging from 1 (not at all) to 5 (to an extreme extent). Ten images receiving the highest scores $(M=4.1$, $\mathrm{SD}=1.12$ ) were selected for use.

To enhance the external validity of the study, peer comments were derived from those found on real Facebook profile-pages, and participants were able to access stimuli from home computers rather than a laboratory site. The images and comments related to the beach, exercise, glamour and/or diet. (Note. all Facebook names were fabricated and photos were obtained via public access to Facebook).

\section{Conventional media stimuli}

Conventional print media stimuli consisted of ten thin-ideal commercial images of models/celebrities with themes matched to those in the Facebook profiles (i.e., beach, exercise, glamour and/or diet). The images consisted of magazine covers or advertisements found in popular magazines and presented in their original format. The same selection criteria used for the Facebook images was applied to the series of 20 Media images; thin-ideal $M=4.3, S D=1.16$.

\section{Manipulation check}

A manipulation check was included to ensure that participants paid adequate attention to the experimental stimuli. Participants were asked to select two pictures that they viewed on the stimuli images out of four possible choices; two stimuli pictures, and two closely matched distractors. Only participants who selected the correct two pictures were included in the analyses.

\section{Measures \\ Demographics}

Participants self reported age, weight, height, ideal weight and race/ethnicity. Self-reported height and weight were used to calculate BMI (weight in kilograms divided by the square of the height in metres).

\section{Facebook use}

Participants self reported the extent and type of their Facebook use including number of years spent using, hours per day, times per day and days per week. Extent of Facebook use scores were calculated by hours per access $\mathrm{x}$ access per day $\mathrm{x}$ days accessed per week.

\section{Type of Facebook use}

Participants were asked how often they engaged in various Facebook activities such as looking at profiles of others and reading comments posted by others on a 5 -point Likert scale ranging from 1 (never) to 5 (always). This metric was used to test the external validity of the stimuli by comparing the extent of similarity between actual Facebook use with experimental stimuli. For this study, the scale showed good reliability (Cronbach's alpha $=.828$ ).

\section{Thin-ideal internalisation}

The 7-item Pressure subscale, one of the four subscales of the Sociocultural Attitudes Toward Appearance Questionnaire-Version 3 (SATAQ-V3) [41], was used to assess perceived pressure from media to attain the thinideal on a 5-point Likert scale ranging from 1 (strongly disagree) to 5 (strongly agree). Items were summed to obtain a score of thin-ideal internalisation at pre-exposure, with a high score indicating high internalisation of the media's thin-ideal. Previous work found that the Pressure subscale (alpha $=.84)$ significantly predicted high BID in a sample of 401 female undergraduates [42]. The scale showed good reliability (Cronbach's alpha $=.83$ ).

\section{Self-esteem}

Rosenberg's Self-Esteem Scale [43] was used to measure baseline self-esteem. This 10 -item scale requires participants to indicate their agreement with each statement on a 4-point Likert scale ranging from 1 (strongly disagree) to 4 (strongly agree). Resulting scores range from 0 to 30 , with higher scores indicating higher self-esteem. A study reported good reliability $(a l p h a=.88)$ among a sample of Australian students [6]. The scale showed good reliability (Cronbach's alpha $=.88$ ). 


\section{Body image dissatisfaction}

The Body Areas Satisfaction Scale (BASS), one of the five subscales of the Multidimensional Body-Self Relations Questionnaire-Appearance Scales (MBSRQ) [44], was used to assess current perceptions of one's body image, asking participants to reflect on their level of satisfaction with nine aspects of their physical appearance, "as you feel right now". For the purpose of the current research question looking at changes in state BID following brief exposure, this subscale was used to measure state BID at pre and post-exposure. Items were scored on a 5-point Likert scale ranging from 1 (very satisfied) to 5 (very dissatisfied), with high scores indicating high state BID. The subscales showed acceptable reliability (Cronbach's alpha $=.789$ ).

The literature shows that baseline BID moderates the relationship between media exposure and subsequent BID [7, 45-47]. Therefore it was necessary to account for pre-exposure BID. Pre-exposure BID scores were subtracted from post-exposure BID scores to create a BID- change score. Negative BID-change scores indicate a decrease in BID from pre to post- exposure, whereas positive BID-change scores indicate an increase in BID from pre to post- exposure.

\section{Appearance comparison}

A 3-item Extent Thoughts Questionnaire [11] was used to measure the extent to which participants had certain thoughts relating to $\mathrm{AC}$ while looking at the experimental images. Items, scored on a 5-point Likert scale ranging from 1 (not at all) to 5 (to an extreme extent), were averaged and summed to obtain a composite measure of AC. Higher scores indicate having experienced AC to a greater extent during exposure to the images. The scale previously showed good reliability $(a l p h a=80)$ in a sample of female undergraduates [11]. For this study, the scale showed excellent reliability (Cronbach's alpha $=.94$ ).

Two additional questions, scored on a 5-point Likert scale ranging from 1 (not at all) to 5 (to an extreme extent), were included to assess the relevance of the stimuli to the individual's actual daily exposure. The first item read, "I personally identify with the persona as shown in the images/Facebook profiles" and higher scores indicated higher personal identification with the stimuli personas. The second item read, "The types of images [and comments] I saw [on the Facebook profiles] are similar to those I see every day [when I sign into my own Facebook]" with higher scores indicating greater similarity between the experimental stimuli and the individual's external exposure to Facebook or conventional media images.

\section{Eating disorder risk}

The Eating Attitudes Test-26 (EAT-26) [48] was used to identify participants at high risk of ED. This 26-item scale was scored on a 6-point Likert scale ranging from
1 (always) to 6 (never). This scale was reported to have excellent reliability $(a l p h a=.90)$ among anorexia nervosa patients [48] and has been used to identify eating disturbances in non-clinical samples [49]. Item scores were summed for an overall test score, ranging from 0 to 78. Using recommendations for non-clinical samples [49], those who receive a score of $20+$ are considered high risk of having an ED. For this study, the scale showed good reliability (Cronbach's alpha $=.870$ ).

\section{Procedure}

The Human Research Ethics Committee of The University of Sydney approved the study. Participants were emailed the participant information statement and given a URL to $\log$ into the questionnaire using Qualtrics software. Clicking onto the questionnaire indicated consent to participate. On completion of the pre-exposure questionnaires (demographics, Facebook use, baseline thin-ideal internalisation, BID and self-esteem) a link randomly allocated participants to one of two conditions:

a) 30-s exposure to each of the ten slides, pertaining to five mock Facebook profile- pages (total $5 \mathrm{~min}$ exposure time; $n=102$ ); or

b) 30-s exposure to ten commercial images of models/celebrities (total 5 min exposure time; $n=91$ ).

After viewing the profiles/images, participants were requested to complete post-exposure questionnaires (manipulation check, state AC, post-BID and ED risk).

\section{Data analyses}

Data was analysed using PASW (SPSS) 20.0 software package. A series of hierarchical multiple regressions tested the relationship between AC and BID-change, and whether the type of exposure moderated this relationship. Multiple regressions were used to determine the relationship between level of Facebook use and baseline BID.

\section{Results}

Extent of Facebook use was positively correlated with pre-BID, EAT-26 scores and AC indicating that greater time spent on Facebook was associated with higher baseline BID, risk for EDs and engagement in AC following exposure to thin-ideal stimuli (see Table 1). Extent of external Facebook activity similar to the activity elicited in the Facebook stimuli was significantly positively correlated with pre-BID, EAT-26 scores, pre-thin ideal pressure and AC. These correlations indicated that greater engagement in Facebook activities, similar to those elicited by the experimental stimuli, was associated with higher baseline BID, risk for EDs, baseline thin-ideal internalisation and engagement in $\mathrm{AC}$ following exposure to thin-ideal stimuli. 
Table 1 Correlation Matrix of Study Variables $(n=193)$

\begin{tabular}{|c|c|c|c|c|c|c|c|c|c|c|c|c|}
\hline & Age & BMI & EAT & Pre-BID & $\begin{array}{l}\text { BID-change } \\
\text { score }\end{array}$ & Pre-Self-esteem & $\begin{array}{l}\text { Pre-Thin-ideal } \\
\text { internalisation }\end{array}$ & $A C$ & $\begin{array}{l}\text { Extent of } \\
\text { Facebook use }\end{array}$ & $\begin{array}{l}\text { Facebook activity } \\
\text { similar to study }\end{array}$ & $\begin{array}{l}\text { Personally identify } \\
\text { with stimuli }\end{array}$ & $\begin{array}{l}\text { Stimuli similar to } \\
\text { everyday exposure }\end{array}$ \\
\hline Age & 1 & $.184^{*}$ & -.001 & -.121 & -.121 & $.222^{* *}$ & -.022 & $-.211^{* *}$ & -.134 & .000 & -.075 & $-.149^{*}$ \\
\hline BMI & & 1 & $.157^{*}$ & $.235^{* *}$ & .011 & -.016 & $.189^{* *}$ & .047 & .003 & .080 & -.118 & -.034 \\
\hline EAT & & & 1 & $.397^{* *}$ & $.172^{*}$ & $-.295^{* *}$ & $.450^{* *}$ & $.494^{* *}$ & $.166^{*}$ & $.180^{*}$ & $.215^{* *}$ & -.008 \\
\hline Pre-BID & & & & 1 & .001 & $-.572^{* *}$ & $.373^{* *}$ & $.485^{* *}$ & $.196^{* *}$ & $.162^{*}$ & .071 & -.048 \\
\hline BID-change score & & & & & 1 & $-.144^{*}$ & $.312^{* *}$ & $.357^{* *}$ & .013 & .091 & .101 & -.095 \\
\hline Pre-Self-esteem & & & & & & 1 & $-.302^{* *}$ & $-.374^{* *}$ & -.069 & -.051 & -.114 & .003 \\
\hline Pre-Thin-ideal internalisation & & & & & & & 1 & $.543^{* *}$ & .120 & $.173^{*}$ & $.150^{*}$ & -.131 \\
\hline$A C$ & & & & & & & & 1 & $.173^{*}$ & $.229^{* *}$ & $.327^{* *}$ & .042 \\
\hline Extent of Facebook use & & & & & & & & & 1 & $.276^{* *}$ & .021 & .108 \\
\hline Facebook activity similar to study & & & & & & & & & & 1 & .051 & .129 \\
\hline Personally identify with stimuli & & & & & & & & & & & 1 & .070 \\
\hline Stimuli similar to everyday exposure & & & & & & & & & & & & 1 \\
\hline
\end{tabular}

Note. BMI, Body Mass Index; EAT, Eating Attitudes Test; Pre-BID, Pre-exposure Body Image Dissatisfaction; BID-change score, Body Image dissatisfaction change score; AC, Appearance Comparison

*. Correlation is significant at the 0.05 level (2-tailed) 
A positive BID-change score indicates an increase in $\mathrm{BID}$, and a negative score, a decrease following exposure. Means and standard deviations for pre-BID, post-BID and BID-change scores in both groups are presented in Table 2.

A hierarchical multiple regression was conducted to test the hypotheses that type of exposure moderated the relationship between AC and BID-change. Since baseline self-esteem and thin- ideal internalization have been shown to moderate the effects of exposure on BID-change [7, 45-47], these two variables were entered on the first line as covariates, followed by type of exposure (dummycoded: Media $=0$, Facebook = 1), AC and their interaction term (with AC mean-centred). Despite the theoretical rationale for BMI [46], it did not significantly correlate with BID-change in the current study and therefore was not included in the analysis.

The full model predicting BID-change from pre-selfesteem, pre-thin-ideal internalisation, $\mathrm{AC}$, exposure and the interaction between $\mathrm{AC}$ and exposure was significant and accounted for $15.7 \%$ of the variance in BID-change, $R^{2}=.157, F(5,187)=6.970, p<.01$; adjusted $R^{2}=.135$. The only significant predictor of BID-change was AC, indicating that, controlling for the other variables in the model, for every one point increase in AC, BID scores are expected to increase by .073 units following exposure $(B=.073$, $t=-3.079, p=.002)$. None of the other variables, including the interaction term, independently predicted BID-change. Table 3 lists the hierarchical multiple regression results.

To test the relationship between $\mathrm{AC}$ and BID-change for each type of exposure, two separate hierarchical multiple regressions were run predicting BID-change from AC for Facebook exposure $(M=-3.108, S D=1.213)$ and media exposure $(M=2.810, S D=1.079)$. In both analyses, thin-ideal internalisation and self-esteem were entered on the first step as covariates, followed by AC.

\section{Media exposure}

For those exposed to media, the full model predicting BID-change from thin-ideal internalisation, self-esteem and AC was significant and accounted for $9.4 \%$ of the variance in BID-change, $R^{2}=.094, F(3,87)=3.017$, $p=.034$; adjusted $R^{2}=.063$. Adding AC did not significantly account for more variance in BID-change above that of thin-ideal internalisation and self-esteem

Table 2 Descriptive Statistics for Pre-BID, Post-BID and BID-Change Scores in Both Exposure Groups

\begin{tabular}{lllllll}
\hline & Pre-BID & & \multicolumn{2}{l}{ Post-BID } & \multicolumn{3}{c}{$\begin{array}{l}\text { BID-change score } \\
\text { (Post-Pre) }\end{array}$} \\
& $M$ & SD & $M$ & SD & $M$ & SD \\
\hline Media $(n=91)$ & 2.939 & .664 & 3.062 & .705 & .123 & .289 \\
Facebook $(n=102)$ & 2.960 & .600 & 3.180 & .677 & .220 & .274 \\
\hline
\end{tabular}

and $\mathrm{AC}$ was not a significant predictor of BID-change for those exposed to media $(B=.054, t=1.440 p=.153)$.

\section{Facebook exposure}

For those exposed to Facebook, the full model predicting BID-change from thin-ideal internalisation, self-esteem and $\mathrm{AC}$ was significant and accounted for $17.3 \%$ of the variance in BID-change, $R^{2}=.173, F(3,98)=6.841$, $p<.01$; adjusted $R^{2}=.148$. Adding $\mathrm{AC}$ significantly accounted for $8.1 \%$ more variance in BID-change above that of thin-ideal internalisation and self-esteem $F(1,98)=9.566, p<.003$. Controlling for thin-ideal internalisation and self-esteem, $\mathrm{AC}$ was a significant predictor of BID-change, indicating that for everyone one point increase in AC, BID scores were expected to increase by .074 points following exposure to Facebook stimuli $(B=.074, t=3.093, p=.003)$. Table 4 lists the hierarchical multiple regression results for each type of exposure.

To test the prediction that the extent of Facebook use would predict baseline BID, a multiple regression analysis was run, controlling for baseline self-esteem, BMI and pre-thin-ideal internalisation (based on theoretical rationale [50] and the significant correlations between these variables and baseline BID). The overall model was significant, accounting for $40.3 \%$ of the variance in baseline BID $R^{2}=.403, F(4,177)=29.880, p<.01$; adjusted $R^{2}=.390$. Controlling for the other predictors in the model, extent of Facebook use was a significant predictor of baseline BID, such that for every one hour increase in Facebook use, BID is expected to increase by .007 points $(B=.007, t=-2.327, p=.021)$. Table 5 lists the multiple regression results.

To determine the degree of perceived similarity between experimental stimuli and Facebook/media images, responses to the question, "the types of images I saw in the stimuli were similar to what I see everyday" were analysed. On average participants exposed to media stimuli found the stimuli significantly more similar to what they reported seeing every day $(M=3.32, S D=1.191)$ compared to those exposed to the Facebook stimuli $(M=1.81$, $S D=1.069), t(1,191)=9.249, p<.001$.

The extent of Facebook use and ED risk was assessed. Participants scoring higher than or equal to 20 on the EAT-26 were considered at high risk, and those less than 20, at low risk for an ED [49]. The average extent of Facebook use was $21.54 \mathrm{~h}$ per week $(S D=16.715)$ for those in the high-risk group and $14.91 \mathrm{~h}$ per week $(S D=11.606)$ for those in the low-risk group.

Extent of Facebook use was not normally distributed across risk groups. A Mann-Whitney $U$ test was therefore run to determine differences in extent of Facebook use between those at high- (EAT-26 score $>=20$, $n=26)$ compared to low-risk (EAT-26 score $<20, n=157$ ) for an ED. 
Table 3 Summary of the Hierarchical Regression Analysis Predicting BID-Change $(n=193)$

\begin{tabular}{|c|c|c|c|c|c|c|c|}
\hline Model & Variable & $B$ & SEB & $\beta$ & $R^{2}$ & $R^{2}$ change & $P$ \\
\hline \multirow[t]{4}{*}{1} & Intercept & -.081 & .162 & & & & \\
\hline & Pre-thin-ideal internalisation & .015 & .004 & .296 & & & $.000^{* *}$ \\
\hline & Pre-self-esteem & -.030 & .040 & -.055 & & & .451 \\
\hline & & & & & .100 & .100 & \\
\hline \multirow[t]{6}{*}{2} & Intercept & -.136 & .178 & & & & \\
\hline & Pre-thin-ideal internalisation & .007 & .004 & .136 & & & .110 \\
\hline & Pre-self-esteem & -.005 & .041 & -.010 & & & .895 \\
\hline & $A C$ & .066 & .020 & .267 & & & $.001^{* *}$ \\
\hline & Exposure & .054 & .041 & .096 & & & .182 \\
\hline & & & & & .155 & .055 & \\
\hline \multirow[t]{7}{*}{3} & Intercept & -.139 & .178 & & & & \\
\hline & Pre-thin-ideal internalisation & .007 & .004 & .136 & & & .108 \\
\hline & Pre-self-esteem & -.013 & .043 & -.023 & & & .764 \\
\hline & $A C$ & .073 & .024 & .298 & & & $.002^{* *}$ \\
\hline & Exposure & .056 & .041 & .098 & & & .172 \\
\hline & $A C^{*}$ exposure & -.022 & .035 & -.057 & & & .540 \\
\hline & & & & & .157 & .002 & \\
\hline
\end{tabular}

Note. The dependent variable was BID-change; $B=$ unstandardized regression coefficient; $S E B=$ standard error of the coefficient; $\beta=$ standardized coefficient; ${ }^{*} p<.05,{ }^{* *} p<.01$

Facebook use scores for high risk (mean rank = 108.04) were statistically significantly higher than for low risk (mean rank $=89.34$ ), $U=1624, \mathrm{z}=-1.669, p=.045$.

\section{Discussion}

To the best of the authors' knowledge, this is the first study to compare Facebook and conventional media in their effects on BID using an experimental design. It was hypothesised that the relationship between $\mathrm{AC}$ and BID-change would be stronger for those exposed to Facebook images compared to those exposed to conventional images. Although $\mathrm{AC}$ was a significant predictor of BID-change for those exposed to Facebook, and not for those exposed to conventional media, type of exposure did not moderate this relationship. In other words, there was no indication of significant differences between Facebook and conventional media in their effects on the relationship between $\mathrm{AC}$ and BID-change. Although unexpected, there are a number of possible explanations why a moderating effect was not obtained.

The relationship between AC and BID is said to occur when one is exposed to thin-ideal content [51, 52]. In the current study, both stimuli represented thin-ideal content. Accordingly, the non-significant moderating role of type of exposure may be due to ceiling effects. The high degree of thin-ideal content in both forms of stimuli may have led both groups to experience high amounts of AC and BID, thus limiting the capacity for differences to be found between the two exposures. Previous studies investigating the effects of thin-ideal exposure on BID compared contrasting stimuli, for example over-weight females versus thin females [53-55], thin-ideal stimuli versus neutral stimuli [17] and attractive females versus objects [7]. Such dissimilar stimuli may facilitate the detection of significant differences; however, these were not deemed to be appropriate for the current study that specifically aimed to delineate the differences between thin-ideal content depicted in conventional and social media. The trends found in the current study indicate that there might be an additive effect of the social component of Facebook on AC.

The finding that exposure did not moderate the relationship between AC and BID-change was also unexpected in light of the assertion that females tend to compare themselves more with similar and self-relevant others [21]. One possible explanation is that participants may have been more familiar with celebrity models depicted in the conventional media stimuli, and hence perceived as more relevant targets of comparison compared to Facebook stimuli, who were completely unknown to the participants $[22,56]$. In response to the statement, "the types of images I saw in the stimuli were similar to what I see everyday", participants exposed to the conventional media indicated that the images in the study were more similar to what they see every day compared to those in the Facebook group. Moreover, females in the Facebook images were selected because they represented the thin-ideal and thus 
Table 4 Comparison of the Hierarchical Regression Analyses Predicting BID-Change for Each Type of Exposure (Media and Facebook)

\begin{tabular}{|c|c|c|c|c|c|c|c|c|c|c|c|c|c|c|c|}
\hline \multirow[b]{2}{*}{ Model } & \multicolumn{8}{|c|}{ Media Exposure $(n=91)$} & \multicolumn{7}{|c|}{ Facebook Exposure $(n=102)$} \\
\hline & Variable & B & SEB & $\beta$ & $t$ & $R^{2}$ & $R^{2}$ change & P & B & SEB & $\beta$ & $t$ & $R^{2}$ & $R^{2}$ change & $P$ \\
\hline & Intercept & -0.077 & 0.267 & & & & & & 0.053 & 0.225 & & & & & \\
\hline \multirow[t]{3}{*}{1} & $\begin{array}{l}\text { Pre-thin-ideal } \\
\text { internalisation }\end{array}$ & 0.014 & 0.007 & 0.238 & 2.011 & & & $0.047^{*}$ & 0.014 & 0.005 & 0.273 & 2.803 & & & $0.006^{* *}$ \\
\hline & Pre-self-esteem & -0.028 & 0.059 & -0.056 & -0.471 & & & 0.639 & -0.056 & 0.059 & -0.093 & -0.952 & & & 0.344 \\
\hline & & & & & & 0.073 & 0.073 & & & & & & 0.092 & 0.092 & \\
\hline \multirow[t]{5}{*}{2} & Intercept & -0.251 & 0.291 & & & & & & -0.050 & 0.219 & & & & & \\
\hline & $\begin{array}{l}\text { Pre-thin-ideal } \\
\text { internalisation }\end{array}$ & 0.009 & 0.007 & 0.161 & 1.25 & & & 0.215 & 0.006 & 0.005 & 0.116 & 1.086 & & & 0.280 \\
\hline & Pre-self-esteem & 0.012 & 0.065 & 0.025 & 0.189 & & & 0.851 & -0.034 & 0.057 & -0.057 & -0.607 & & & 0.545 \\
\hline & $\begin{array}{l}\text { Appearance } \\
\text { comparison }\end{array}$ & 0.054 & 0.037 & 0.200 & 1.440 & & & 0.153 & 0.074 & 0.024 & 0.330 & 3.093 & & & $0.003^{* *}$ \\
\hline & & & & & & 0.094 & 0.022 & & & & & & 0.173 & 0.081 & \\
\hline
\end{tabular}

Note. The dependent variable was BID-change; $B=$ unstandardized regression coefficient; SEB = standard error of the coefficient; $\beta=$ standardized coefficient ${ }^{*} p<.05,{ }^{* *} p<.01$

did not look vastly different from the models in the media stimuli. Consequently, the participants may have perceived the Facebook 'friends' as models, similar to those in the conventional media images.

It has been suggested that Facebook friends, who are usually highly similar and socially relevant to the Facebook user, may elicit more significant comparative processes [57]. Given the media stimuli were perceived as more relevant and familiar to participants in the current study, the non-significant differences between the two groups may indicate that the experimental stimuli were not able to elicit the social nuances distinctive to Facebook profiles. Thus, future studies comparing the effects of Facebook and conventional media images on AC and BID should aim to use Facebook profiles pertaining to the participants' actual peers.

Finally, the non-significant differences may indicate that Facebook and conventional media may be comparable in their effects on AC and BID. This has implications both theoretically and practically, given that thin-ideal images in

Table 5 Summary of the Multiple Regression Analysis Predicting Baseline BID $(n=193)$

\begin{tabular}{llllll}
\hline Variable & $B$ & SEB & $\beta$ & $R^{2}$ & $P$ \\
\hline Intercept & 3.473 & .337 & & & \\
Pre-self-esteem & -.608 & .075 & -.487 & & $.000^{* *}$ \\
Pre-thin-ideal internalisation & .021 & .007 & .182 & $.004^{* *}$ \\
BMl & .029 & .009 & .195 & $.001^{* *}$ \\
Extent of Facebook use & .007 & .003 & .136 & $.021^{*}$ \\
& & & & .403 & \\
\hline
\end{tabular}

Note. The dependent variable was baseline BID; $B=$ unstandardized regression coefficient

SEB $=$ standard error of the coefficient; $\beta=$ standardized coefficient; ${ }^{*} p<.05,{ }^{* *} p<.01$ conventional media have consistently been found to have detrimental effects on BID and broader mental health issues [7, 16, 47, 58-60]. Moreover, there is increasing evidence of the high user rates of Facebook and other SNSs over that of conventional media [19]. The present results indicate that Facebook, like conventional media, may play a similar role in the development of BID.

The hypothesis that higher Facebook use is associated with higher baseline BID was supported. Furthermore, results indicated that the extent of Facebook use accounted for unique variance in baseline BID above that of selfesteem, BMI and thin-ideal internalisation, variables already established as risk factors for BID [46]. This finding suggests that high Facebook use may be considered a risk factor for BID, even when controlling for self-esteem, BMI and thin-ideal internalisation.

Of interest was the considerably higher average Facebook use in the current sample compared to previous frequency studies. Whereas the average use in Australia is $15.55 \mathrm{~h}$ per month [31], the average use in the current sample was $15.78 \mathrm{~h}$ per week (i.e., greater than $60 \mathrm{~h}$ per month). This notably higher use may be due to the fact that the sample was comprised of only females, the dominant gender in Facebook use within the age group with the highest reported Facebook use [31]. In light of these demographics, the higher Facebook use in the current study may not be surprising. Nevertheless, caution should be taken when generalising the current findings to older samples or the general population.

An important finding was the relationship between Facebook use and ED risk. Post-hoc analyses revealed that Facebook use was significantly higher for those at high risk of EDs compared to those at low risk. This finding was consistent with a recent survey that found 
an association between time spent on Facebook and ED pathology [37]. The correlational finding could indicate that excessive Facebook use is associated with an individual's risk of developing an ED. The integrated cognitive-behavioural theory of EDs [61] identifies a feedback loop whereby exposure to body-related stimuli activates and reinforces an over- concern with one's own body, which in turn reactivates attentional biases toward body- related stimuli. The frequency of this feedback loop serves to generate or maintain EDs [61] and this process could possibly explain the finding of a relationship between frequent Facebook use and ED risk. Accordingly, it may be the case that frequent exposure to thinideal content on Facebook reinforces one's own bodyrelated concerns, eliciting cognitive biases that lead one to selectively attend to thin-ideal content on Facebook [37].

On the other hand, it may be possible that people with a higher risk of EDs are more likely to use Facebook, which may in turn serve to reinforce their ED risk [62]. Cognitive models of EDs posit that individuals with EDs show a selective attention for appearance-related cues [61]. Thus, the current study's finding of an association between ED risk and high Facebook use could imply that people with EDs may be more vulnerable to the negative effects of Facebook. Either way, the current results highlight the need for further research into the relationship between ED risk and Facebook use. Moreover, this study operationalized ED risk using recommendations for a non-clinical sample [49]. Future research with clinically diagnosed ED samples may prove to be more useful in examining the role of Facebook use in the development and maintenance of EDs.

As in all studies there are limitations. All data collected was self-report, including self- reported weight and height, which is subject to recall errors or biased reporting. A main caveat of the current study is a lack of external validity for the Facebook stimuli, which contained mock personas rather than the participants' actual peers. Therefore Facebook's additional peer-relevant component was less salient. The current study attempted to increase external validity by designing stimuli that replicated real Facebook profile-pages, with participants able to access the experimental stimuli from their own computer at leisure.

Another potential limitation was that the current study only included female 'friends' without also including comments by male 'friends'. The Catalyst Model [63] argues that BID is a direct outcome of competition between females for mates. In social contexts, women understand that they are competing for sexual partners with their peers, in contrast to models or celebrities where there is no perceived competition [64]. Furthermore, female AC tendencies have been found to be heightened in the context of potential male partners [65]. Given that
Facebook friends typically consist of both females and males, and that Facebook is used to develop or maintain both social and romantic relationships, it may have been informative to include both male and female images and comments in the experimental stimuli. It is possible that these additions may have led to increased $\mathrm{AC}$ and thus greater BID than for those exposed to conventional media images, void of a social or romantic context.

It is also possible that the difference between conventional media and Facebook exposure was not evident in this short-term study, but may have a differential influence on BID in the long-term. It has been argued that whilst it may be difficult to capture the effects of a brief exposure to thin-ideal images in a laboratory setting, continuous exposure to thin-ideal media in everyday life may serve to reinforce BID in the long-term $[10,60]$. The duration of the exposure to Facebook images in the current study was $5 \mathrm{~min}$ in total whereas the average amount of time per Facebook access is typically $20 \mathrm{~min}$, numerous times a day [31]. Moreover, the trends in the current study showed that AC was greater for those exposed to Facebook than conventional media. Therefore despite the fact that there were no significant findings of an acute effect of exposure to Facebook on BID over conventional media in the present study, it is plausible that continued exposure to Facebook thin-ideal content could have dire effects in the long-term, above that of conventional media [60]. Longitudinal research is needed to further examine the long-term effects of such a relationship.

\section{Conclusion}

This study's findings have several theoretical and practical implications. The current study's finding that the relationship between AC and BID was comparable between Facebook and conventional media, suggests that Facebook, and potentially other SNSs, are key factors that need to be considered in the development of BID.

Additionally, the finding that $\mathrm{AC}$ is affected by Facebook, not just conventional media, suggests that interventions should focus on how people compare themselves with peers in social media, in addition to how they view models in conventional media images. The finding of an association between the extent of Facebook use and ED risk indicates that, although thin-ideal forums such as Facebook do not cause EDs, they may be one of many maintaining factors, reinforcing an over-evaluation of weight and shape [61].

Although this explorative study failed to demonstrate that the relationship between AC and BID is stronger following exposure to Facebook than conventional media in the short-term, it suggested that exposure to Facebook is at least on par with conventional media exposure in its detrimental effects on BID via AC. 
The present study contributes to the existing literature on the media's influence on BID by expanding upon a narrow focus on conventional media only by exploring emerging social media formats.

\section{Abbreviations}

BID: Body image dissatisfaction; BID-Change: Body image dissatisfaction change score; AC: Appearance comparison; ED: Eating disorder; BMI: Body mass index; SNS: Social networking site.

\section{Competing interests}

The authors declare that they have no competing interests.

\section{Authors' contributions}

$\mathrm{RC}$ carried out the study, ran the statistical analyses and drafted the manuscript. $A B$ supervised throughout and revised the manuscript accordingly. All authors read and approved the final manuscript.

\section{Acknowledgements}

None.

Received: 7 April 2014 Accepted: 21 May 2015

Published online: 02 July 2015

\section{References}

1. Fisher S. Development and structure of the body image. Erlbaum Hillsdale: NJ; 1986.

2. Graber JA, Brooks-Gunn J, Paikoff RL, Warren MP. Prediction of eating problems: an 8- year study of adolescent girls. Dev Psychol. 1994;30(6):823.

3. Stice E. A prospective test of the dual-pathway model of bulimic pathology: mediating effects of dieting and negative affect. J Abnorm Psychol. 2001:110(1):124

4. Wertheim EH, Koerner J, Paxton SJ. Longitudinal predictors of restrictive eating and bulimic tendencies in three different age groups of adolescent girls. J Youth Adolesc. 2001;30(1):69-81.

5. Kenardy J, Brown WJ, Vogt E. Dieting and health in young Australian women*. Eur Eat Disord Rev. 2001;9(4):242-54.

6. Rodgers R, Chabrol H, Paxton S. An exploration of the tripartite influence model of body dissatisfaction and disordered eating among Australian and French college women. Body Image. 2011;8(3):208-15.

7. Posavac HD, Posavac SS, Posavac EJ. Exposure to media images of female attractiveness and concern with body weight among young women 1. Sex Roles. 1998;38(3-4):187-201.

8. Tiggemann M, McGill B. The role of social comparison in the effect of magazine advertisements on women's mood and body dissatisfaction. T J Soc Clin Psychol. 2004;23(1 Special Issue: Body Image and Eating Disorders: Influence of Media Images):23-44.

9. Grabe S, Ward L, Hyde JS. The role of the media in body image concerns among women: a meta-analysis of experimental and correlational studies. Psychol Bull. 2008;134(3):460-76.

10. Hausenblas HA, Campbell A, Menzel JE, Doughty J, Levine M, Thompson JK. Media effects of experimental presentation of the ideal physique on eating disorder symptoms: a meta-analysis of laboratory studies. Clin Psychol Rev. 2013;33(1):168-81.

11. Bessenoff GR. Can the media affect us? Social comparison, self-discrepancy, and the thin ideal. Psychol Women Q. 2006;30(3):239-51.

12. Homan K, McHugh E, Wells D, Watson C, King C. The effect of viewing ultra-fit images on college women's body dissatisfaction. Body Image. 2012;9(1):50-6.

13. Irving LM. Mirror images: effects of the standard of beauty on the self-and body-esteem of women exhibiting varying levels of bulimic symptoms. J Soc Clin Psychol. 1990;9(2):230-42.

14. Richins ML. Social comparison and the idealized images of advertising J Consum Res. 1991:18:71-83.

15. Schutz HK, Paxton SJ, Wertheim EH. Investigation of body comparison among adolescent girls1. J Appl Soc Psychol. 2002;32(9):1906-37.

16. Stice $E$, Shaw HE. Adverse effects of the media portrayed thin-ideal on women and linkages to bulimic symptomatology. J Soc Clin Psychol. 1994;13(3):288-308.

17. Tiggemann $M$, Slater $A$. Thin ideals in music television: a source of social comparison and body dissatisfaction. Int J Eat Disord. 2004;35(1):48-58.
18. van den Berg P, Paxton SJ, Keery H, Wall M, Guo J, Neumark-Sztainer D. Body dissatisfaction and body comparison with media images in males and females. Body Image. 2007;4(3):257-68.

19. Bair CE, Kelly NR, Serdar KL, Mazzeo SE. Does the Internet function like magazines? An exploration of image-focused media, eating pathology, and body dissatisfaction. Eat Behav. 2012;13(4):398-401.

20. Ryan T, Chester A, Reece J, Xenos S. The uses and abuses of facebook: a review of facebook addiction. J Behav Addict. 2014;3(3):133-48.

21. Festinger $\mathrm{L}$. A theory of social comparison processes. Human Relations. 1954:7(2):117-40.

22. Jones D. Social comparison and body image: attractiveness comparisons to models and peers among adolescent girls and boys. Sex Roles. 2001;45(9-10):645-64. doi:10.1023/a:1014815725852.

23. Haferkamp N, Eimler SC, Papadakis A-M, Kruck JV. Men are from Mars, women are from Venus? Examining gender differences in self-presentation on social networking sites. Cyberpsychol Behav Soc Netw. 2012;15(2):91-8.

24. Haferkamp N, Kramer NC. Social comparison 2.0: examining the effects of online profiles on social-networking sites. Cyberpsychol Behav Soc Netw. 2011;14(5):309-14.

25. Rodgers R, Melioli T, Laconi S, Bui E, Chabrol H. Internet addiction symptoms, disordered eating, and body image avoidance. Cyberpsychol Behav Soc Netw. 2013;16(1):56-60.

26. Reaves S, Bush Hitchon J, Park S-Y, Woong YG. If looks could kill: digita manipulation of fashion models. J Mass Media Ethics. 2004;19(1):56-71.

27. Bissell K, editor. The virtual model: College women's knowledge of digital manipulation in fashion photographs and body image distortion. Annual meeting of the International Communication Association, New Orleans Sheraton, New Orleans, LA. 2004.

28. Boyd D, Ellison N. Social network sites: definition, history, and scholarship. J Comput Mediat Commun. 2007;13(1):210-30. doi:10.1111/j.10836101.2007.00393.x.

29. Duggan M, Brenner J. The demographics of social media users, 2012. Pew Research Center's Internet \& American Life Project; 2013. Retrieved from: http://www.pewinternet.org/2013/02/14/the-demographics-of-social-mediausers-2012/.

30. Facebook. Facebook facts. 2013. http://newsroom.fb.com/Key-Facts. Accessed 7 April, 2013.

31. Socialbakers. Australia facebook statistics by countries. 2013 http://www.socialbakers.com/facebook-statistics/australia.

32. Nichter M, Vuckovic N. Fat talk. In: Sault N, editor. Many mirrors: body image and social relations. New Brunswick: Rutgers University Press; 1994. p. 109-32.

33. Arroyo A, Harwood J. Exploring the causes and consequences of engaging in fat talk. J Appl Commun Res. 2012;40(2):167-87.

34. Villiard H, Moreno MA. Fitness on facebook: advertisements generated in response to profile content. Cyberpsychol Behav Soc Netw. 2012;15(10):564-8

35. Clemmer K. Body image friend or foe? How is facebook affecting the way you feel about your body? The Center for Eating Disorders Blog; 2012. Retrieved from: http://eatingdisorder.org/blog/2012/03/body-image-friendor-foe-how-is-facebook- affectingthe-way-you-feel-about-your-body/

36. Taniguchi E, Lee HE. Cross-cultural differences between Japanese and American female college students in the effects of witnessing fat talk on facebook. J Intercult Commun Res. 2012;41(3):260-78.

37. Latzer $Y$, Katz R, Spivak Z. Media exposure disordered eating and sense of empowerment among adolescents girls: the importance of parental involvement. Society \& Welfare, ("Hevra Verevaha"). 2012;33:415-44.

38. Tiggemann M, Slater A. NetGirls: the internet, facebook, and body image concern in adolescent girls. Int J Eat Disord. 2013;46(6):630-3.

39. Cohen J. Statistical power analysis for the behavioral sciencies. 2nd ed Hillsdale, NJ: Laurence Erlbaum Associates; 1988.

40. Faul F, Erdfelder E, Lang A-G, Buchner A. G* Power 3: a flexible statistical power analysis program for the social, behavioral, and biomedical sciences. Behav Res Methods. 2007;39(2):175-91.

41. Thompson J, van den Berg P, Roehrig M, Guarda A, Heinberg L. The sociocultural attitudes towards appearance scale-3 (SATAQ-3): development and validation. Int J Eat Disord. 2004;35(3):293-304. doi:s10.1002/eat.10257.

42. Swami V, Taylor R, Carvalho C. Body dissatisfaction assessed by the photographic figure rating scale is associated with sociocultural, personality, and media influences. Scand J Psychol. 2011;52(1):57-63.

43. Rosenberg M. Society and the adolescent self-image. Princeton NJ: Princeton University Press; 1965. 
44. Cash TF. Body image. In: Kazdin A, editor. The encyclopedia of psychology. Washington, D.C.: American Psychological Association and Oxford University Press; 2000. p. 436-9.

45. Durkin SJ, Paxton SJ. Predictors of vulnerability to reduced body image satisfaction and psychological wellbeing in response to exposure to idealized female media images in adolescent girls. J Psychosom Res. 2002;53(5):995-1005.

46. Durkin SJ, Paxton SJ, Sorbello M. An integrative model of the impact of exposure to idealized female images on adolescent girls' body satisfaction1. J Appl Soc Psychol. 2007;37(5):1092-117. doi:10.1111/j.1559-1816.2007.00201.x

47. Groesz LM, Levine MP, Murnen SK. The effect of experimental presentation of thin media images on body satisfaction: a meta analytic review. Int J Eat Disord. 2002;31(1):1-16.

48. Garner DM, Olmsted MP, Bohr Y, Garfinkel PE. The eating attitudes test: psychometric features and clinical correlates. Psychol Med. 1982;12(4):871-8.

49. Willinge A, Touyz S, Charles M. How do body-dissatisfied and body-satisfied males and females judge the size of thin female celebrities? Int J Eat Disord. 2006;39(7):576-82.

50. Stice E, Shaw HE. Role of body dissatisfaction in the onset and maintenance of eating pathology: a synthesis of research findings. J Psychosom Res. 2002;53(5):985-93.

51. Kalpidou M, Costin D, Morris J. The relationship between Facebook and the well-being of undergraduate college students. Cyberpsychol Behav Soc Netw. 2011;14(4):183-9.

52. Van den Berg P, Thompson JK, Obremski-Brandon K, Coovert M. The tripartite influence model of body image and eating disturbance: a covariance structure modeling investigation testing the mediational role of appearance comparison. J Psychosom Res. 2002;53(5):1007-20.

53. Dalley SE, Buunk AP, Umit T. Female body dissatisfaction after exposure to overweight and thin media images: the role of body mass index and neuroticism. Pers Individ Dif. 2009;47(1):47-51.

54. Roberts A, Good E. Media images and female body dissatisfaction: the moderating effects of the five-factor traits. Eat Behav. 2010;11(4):211-6.

55. Tucci S, Peters J. Media influences on body disatisfaction in female students. Psicothema. 2008;20(4):521-4

56. Strahan EJ, Wilson AE, Cressman KE, Buote VM. Comparing to perfection: How cultural norms for appearance affect social comparisons and self-image. Body Image. 2006;3(3):211-27.

57. Krasnova H, Wenninger $H$, Widjaja T, Buxmann P. Envy on Facebook: A Hidden Threat to Users' Life Satisfaction? Presented at the 11th International Conference on Wirtschaftsinformatik (WI), Leipzig, Germany. 2013.

58. Lavine H, Sweeney D, Wagner SH. Depicting women as sex objects in television advertising: effects on body dissatisfaction. Pers Soc Psychol Bull. 1999;25(8):1049-58.

59. Stice E. Review of the evidence for a sociocultural model of bulimia nervosa and an exploration of the mechanisms of action. Clin Psychol Rev. 1994;14(7):633-61.

60. Tiggemann M. Media influences on body image development. In: Cash TF, Pruzinsky T, editors. Body image: a handbook of theory, research, and clinical practice. New York NY: The Guilford Press; 2002. p. 91-8.

61. Williamson DA, White MA, York-Crowe E, Stewart TM. Cognitive-behavioral theories of eating disorders. Behav Modif. 2004;28(6):711-38.

62. Cho A, Kwak S-M, Lee J-H. Identifying attentional bias and emotional response after appearance-related stimuli exposure. Cyberpsychol Behav Soc Netw. 2013;16(1):50-5.

63. Ferguson CJ, Winegard B, Winegard BM. Who is the fairest one of all? How evolution guides peer and media influences on female body dissatisfaction. Rev Gen Psychol. 2011;15(1):11.

64. Ferguson CJ, Munoz ME, Garza A, Galindo M. Concurrent and prospective analyses of peer, television and social media influences on body dissatisfaction, eating disorder symptoms and life satisfaction in adolescent girls. Journal of Youth and Adolescence Jan. 2013 (Pagination):No Pagination Specified

65. Vandenbosch L, Eggermont S. Understanding sexual objectification: a comprehensive approach toward media exposure and girls' internalization of beauty ideals, self- objectification, and body surveillance. J Commun. 2012;62(5):869-87. doi:10.1111/j.1460- 2466.2012.01667.x.

\section{Submit your next manuscript to BioMed Central and take full advantage of:}

- Convenient online submission

- Thorough peer review

- No space constraints or color figure charges

- Immediate publication on acceptance

- Inclusion in PubMed, CAS, Scopus and Google Scholar

- Research which is freely available for redistribution

Submit your manuscript at www.biomedcentral.com/submit 